\title{
Influence of learning-style preferences in academic performance in the subject of human anatomy: an institution-based study among preclinical medical students
}

This article was published in the following Dove Press journal:

Advances in Medical Education and Practice

\section{Khanal' \\ J Giri ${ }^{2}$ \\ S Shah' \\ S Koirala' \\ J Rimal ${ }^{2}$}

'Department of Human Anatomy, BP Koirala Institute of Health Sciences,

Dharan, Nepal; ${ }^{2}$ Department of Medical Education, BP Koirala Institute of Health Sciences, Dharan, Nepal

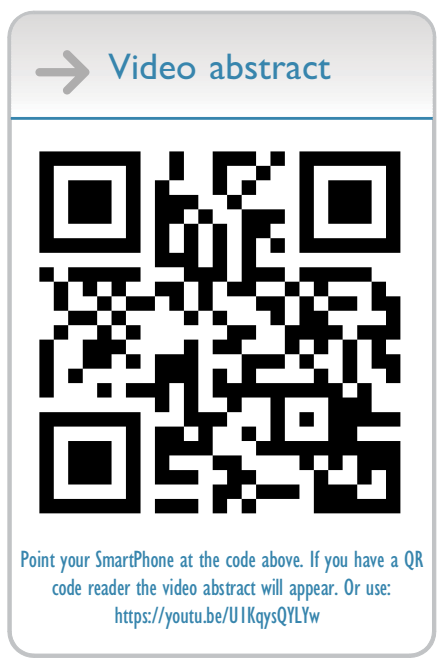

Correspondence: L Khanal

Department of Human Anatomy, BP Koirala Institute of Health Sciences, PO

Box 7053, Dharan, Nepal

Tel +977986492 7925

Email laxman.khanal@bpkihs.edu
Purpose: The present study was conducted to find the preferred mode of learning among first-year preclinical students and compare the preferred mode of learning with sex, faculty of students, and academic performance of the students using the VARK questionnaire.

Methods: A cross-sectional study was done among 142 first-year Bachelor of MedicineBachelor of Surgery and Bachelor of Dental Surgery students from February to May 2018. Demographic data and various academic performance marks were recorded for each individual. VARK (visual, aural, read/write and kinesthetic) questionnaire version 7.8 was administered to calculate the score of each component. Mean VARK scores were calculated and each student classified by their preferred mode of learning. The preferred mode of learning was compared with sex, nationality, faculty of students, and academic performance using $\chi^{2}$, unpaired $t$-tests, and the Mann-Whitney $U$ test. $P<0.05$ was taken as statistically significant for comparison.

Results: A majority of the students $(53.52 \%)$ were multimodal. The most common multimodal mode of preference was bimodal $(26.06 \%$ ), while the most common unimodal preference was kinesthetic (29.06\%). Total V score, K score, and VARK score were higher among males, while A and R scores were higher among females. The K score $(7.96 \pm 2.35$ in males and $6.96 \pm 2.43$ in females) differed significantly $(P=0.019)$ between male and female subjects. More subjects with higher scores in the theory exam of anatomy were unimodal learners (53.8\%) compared to multimodal learners (46.2\%).

Conclusion: From this study, it can be concluded that undergraduate students were diverse in their learning styles, but most were multimodal. Though learning styles were found to vary by sex, nationality, and academic performance, differences were not statistically significant.

Keywords: academic performance, learning preference, medical education, VARK

\section{Introduction}

The BP Koirala Institute of Health Sciences (BPKIHS) is an autonomous healthscience university of Nepal that has implemented a need-based, integrated, partial problem-solving, and community-oriented curriculum, conceptualized in the Edinburgh Declaration of $1988 .^{1}$

"Learning style" was defined by Keefe in 1979 as "the composite of characteristic cognitive, affective, and physiological factors that serve as relatively stable indicators of how a learner perceives, interacts with, and responds to the learning environment". 2 Although a large number of learning styles and strategies are formulated based upon 
various psychological constructs, educators are interested in identifying learners based on visual, auditory, read/write, or kinesthetic (VARK) preferences of learning. ${ }^{3}$

The dramatic increase in the volume of content from undergraduate education to the initial phase of medical school is one of the biggest difficulties for most students. Furthermore, the diversity of the student body in terms of age, experience, culture, and level of preparedness, as well as learning preferences and styles, creates challenges for medical instructors to meet the educational needs of the students. In a precise sense, motivation and performance of the student improves when the instruction is in accordance with their learning preferences and styles. Because of the diversity in learning styles, students often find a mismatch between their learning and the delivery of instruction. They have the tendency to seek information that is methodically and efficiently presented to them. ${ }^{4}$ It is the responsibility of the instructor to deliver their lesson planappropriatelyby accepting the diversity of learning styles. ${ }^{5}$

To overcome the possibility of treating all students the same way, knowledge of their learning styles seems helpful to educators. This knowledge can also be a useful asset in identifying the learning problems of students and making them effective learners. ${ }^{5,6}$

Many factors like sex, age, academic achievement, and thinking styles can influence student learning styles. ${ }^{7}$ It is important to know that students remember $20 \%$ of the information they read, $30 \%$ of what they hear, $40 \%$ of what they see, $50 \%$ of what they say, and $60 \%$ of what they do. This becomes $90 \%$ for information they say, hear, see, and do. ${ }^{8}$ Learners can be defined based on the sensory modality by which they prefer to get or deliver new information. Fleming and Miles defined four sensory modalities of learning: visual (V), aural (A), read/write (R) and kinesthetic $(\mathrm{K})$, together referred to as VARK. ${ }^{9}$ Students with a visual preference prefer to explain concepts by drawing pictures and diagrams. Students with an aural preference prefer to receive or give information by listening and talking. Students with a read-write preference can easily understand concepts using lists, handouts, and textbooks. Students with a kinesthetic preference favor a hands-on approach, trial and error, and real-life examples. The VARK questionnaire can identify whether a student has a strong learning preference for one of the modalities or is a flexible learner who can learn using two or more sensory modalities, as revealed by a number of crosssectional studies. $5,6,9,10,11$
Anatomy is considered an important component of the curriculum in medical schools. Knowledge of anatomy remains central to medical students' training in various disciplines. For effective teaching in anatomy, it is important for instructors to understand learning styles of their students. ${ }^{12,13}$ Knowledge of dissection in anatomy is mainly gained by doing, which has also been found to be positively associated with academic success in courses involving more kinesthetic activities. ${ }^{14}$ Although a number of studies with inconsistent results are available from various parts of the world, there is a lack of information about the distribution of learning preferences of medical students in Nepal, where the culture of medical education differs from other countries. This cultural diversity of students adds to the diversity of their learning styles and strategies. ${ }^{15}$ Rethinking and reframing organizational culture within the medical education system has been the critical demand in Nepal. The need for lifelong learning of medical personnel should be apparent from the very early stages of medical training, but a study on students' perception of medical education in Nepal showed that a majority are not getting the necessary knowledge from the preclinical stage. Information and communication technology is vital for medical education in the 21 st century, but is not able to satisfy the needs of the majority of students. Similarly, other challenging issues are inadequate integration of basic science subjects with clinical relevance, inadequate time devoted to instruction in long-term health care, inconsistency of the curriculum among medical schools, and inadequate learning of communication skills, ethics, and moral and leadership development. ${ }^{16,17}$ This study was conducted to determine learning styles and their relationship with the academic performance of medical students studying in Nepal.

\section{Methods}

This was a cross-sectional questionnaire-based study carried out at BP Koirala Institute of Health Science, Dharan, Nepal from February to May 2018. Ethical clearance was received in May 2017 from the institutional review committee (445/073/074-IRC).

\section{Data collection}

The information included demographic details, such as sex, age, nationality (Indian, Nepali, and other), grades (percentage) they obtained in at higher secondary level $(10+2)$ and in the first-unitanatomyexam, and study hours per week. The latest English version of the VARK questionnaire (version 
7.8), which consists of 16 multiple-choice questions, was administered after the first internal exam of first-year medical students to determine their preferred mode(s) of learning. Permission was obtained from the VARK author through the VARK website (http://www.vark-learn.com). The VARK questionnaire was selected because it is concise and quick to complete and each question aims to place respondents in a "learning" situation. The purpose of the study was explained to the students. They were informed verbally that there were no right or wrong answers, and thus their answers should represent what they would really do in the context of each question and not what they believe is expected to be done. All choices corresponded to the four learning preferences: visual, aural, $\mathrm{read} / \mathrm{write}$, and kinesthetic. Students could select one or more choices for each question, skip a question, or choose two or more options if appropriate. Reliability estimates for scores of VARK subscales determined by Leite et al were $0.85,0.82$, 0.84 , and 0.77 for the visual, aural, read/write and kinesthetic subscales, respectively. These were considered adequate. ${ }^{18}$ The validity of the questionnaire has been assessed in a few studies. Rasch analysis suggested that the instrument could be used as a predictor of a person's learning-preference orientation. ${ }^{19}$ Another study using a quasiexperimental design showed that word-spelling gains were highest when the teaching mode matched the learning-style preference. ${ }^{20}$ In an item analysis using the correlated trait-correlated uniqueness model, values of standardized loading of items ranged 0.24 0.76 , with mean loading of $0.51,0.47,0.50$, and 0.41 for visual, aural, read/write, and kinesthetic factors, respectively. ${ }^{18}$ The risk of asking personal information like marks obtained in higher secondary level was overcome by assuring privacy regarding disclosure of the information, and confidentiality was maintained.

\section{Inclusion criteria}

Preclinical first-year medical students (Bachelor of Medicine-Bachelor of Surgery [MBBS] and Bachelor of Dental Surgery [BDS]) participated in the study. Only students who completed the questionnaire were evaluated.

\section{Exclusion criteria}

Students who were absent on the day of the study or who did not complete the questionnaire properly were not included.

\section{Data-collection method}

Data collection was done during practical sessions of anatomy in the dissection hall. Data were collected after taking written informed consent from the students. VARK version 7.8 with 16 questions was administered, along with a semistructured questionnaire containing demographic details like age, sex, nationality, study hours per week, and academic performance.

\section{Data entry and analysis}

Data were entered in Microsoft Excel, then transferred to SPSS version 20 for analysis. The qualitative variables sex, nationality, and ethnicity were entered into Excel spreadsheets using numerical coding. First, descriptive statistics like frequency, mean, range, and SD were derived and different graphs and charts built to show the distribution of data points. To assess associations of two categorical variables, $\chi^{2}$ for association was conducted. Further, Student's $t$-test and the Mann-Whitney $U$ test were used to assess difference between binomial categorical variables ( male vs female, unimodal vs multimodal learners). At the end, correlations were tested between variables using Spearman's correlation test. All statistical values were taken as significant at $P<0.05$. Outcome variables were VARK score, total V score, total A score, total R score, and total K score.

\section{Study site}

The study was carried out in the dissection hall of the Department of Anatomy.

\section{Sampling method}

Convenience sampling was used. All preclinical medical students were approached, and those who gave consent were enrolled till the desired sample size was achieved.

\section{Sample size}

The minimum sample size was 133. Sample size was calculated by applying a priori power analysis using G*Power software. $^{21}$ All first- year MBBS and BDS students were asked to fill in the questionnaire, and finally 142 students were enrolled.

\section{Results}

This study was conducted among 142 preclinical students enrolled in the first year of MBBS (98) or BDS (44) at the BPKIHS in 2017. The proportion of males to females was 1.84. By nationality, $73.2 \%$ were Nepalese and $26.8 \%$ Indian. Ages of subjects ranged 17-23 years with mean age $19.57 \pm 1.15$ years. Academic marks secured in grade 12 (or equivalent) were $>80 \%$ in $43 \%$ of subjects. Similarly, study hours per week were found to be $>50$ in 
$19.7 \%$ of subjects. Academic performance in the subject of human anatomy during the first-unit exam was also recorded for both theory and objective structured practical examinations. Subjects were categorized as high achievers and low achievers on the basis of the marks they secured. Among them, 28.1\% and 32.4\% achieved $>60 \%$ (high achievers) in theory and practical, respectively. Detailed descriptive statistics of the different variables are shown in Tables 1 and 2 .

Learning-style preferences of the students were also computed using the stepping-distance method (Table 3). Multimodal and unimodal preferences were found in $53.52 \%$ and $46.48 \%$ of students, respectively. Among multimodal learners, the most common mode of preference was bimodal (26.06\%), followed by quadrimodal (16.2\%) and trimodal (11.27\%; Table 3$)$.

Similarly, among the unimodal learners with only one component of VARK, 29.6\% were kinesthetic learners followed by aural, visual and read/write. The most preferred mode among bimodal and trimodal learners was $\mathrm{AK}$ (18.3\%) and ARK (5.6\%) (Table 3). Distribution of student's preferred learning style between genders, nationality and academic performance is shown in bar diagram (Figures 1 and 2).

Comparison between unimodal and multimodal learning was done, with many categorical variables revealing subjects' sociobiological and academic characteristics, as depicted in Tables 4 and 5. Tests of association were carried out using $\chi^{2}$. Table 4 shows that multimodal learning was preferred in both MBBS and BDS students, in both sexes, and also in both nationalities. Distribution of learning modalities was almost equally distributed among MBBS students, while more BDS students (59.1\%) were found to have multimodal preferences. When tested for statistical significance, none of the characteristics was significantly associated with modes of learning $(P>0.05)$.

To visualize the distribution of the study sample in different academic parameters, students were categorized into

Table I Frequency distribution of variables defining the study population

\begin{tabular}{|c|c|c|c|}
\hline Variables & Categories & Frequency & Percentage \\
\hline \multirow[t]{2}{*}{ Faculty of students $(n=142)$} & MBBS & 98 & 69.0 \\
\hline & BDS & 44 & 31.0 \\
\hline \multirow[t]{2}{*}{ Gender $(n=\mid 42)$} & Male & 92 & 64.8 \\
\hline & Female & 50 & 35.2 \\
\hline \multirow[t]{2}{*}{ Nationality $(n=142)$} & Nepalese & 104 & 73.2 \\
\hline & Indian & 38 & 26.8 \\
\hline \multirow{2}{*}{ Age-group $(n=\mid 42)$} & $<20$ year & 73 & 51.4 \\
\hline & $\geq 20$ year & 69 & 48.6 \\
\hline \multirow[t]{2}{*}{ Higher secondary school score $(n=142)$} & High achiever & 61 & 43.0 \\
\hline & Low achiever & 16 & 11.3 \\
\hline \multirow[t]{2}{*}{ Study hours per week $(n=\mid 42)$} & $\leq 40$ & 57 & 40.1 \\
\hline & $>50$ & 28 & 19.7 \\
\hline \multirow[t]{2}{*}{ Score in theory exam of anatomy $(n=139)$} & High achiever & 39 & 28.1 \\
\hline & Low achiever & 57 & 41.0 \\
\hline \multirow[t]{2}{*}{ Score in practical exam of anatomy $(n=139)$} & High achiever & 45 & 32.4 \\
\hline & Low achiever & 48 & 34.5 \\
\hline
\end{tabular}

Abbreviations: MBBS, Bachelor of Medicine-Bachelor of Surgery; BDS, Bachelor of Dental Surgery.

Table 2 Study-population variables

\begin{tabular}{|l|l|l|l|}
\hline & Mean (SD) & Spread & Range \\
\hline Age $(n=142)$ & $19.57(1.15)$ & 6.00 & $17.00-23.00$ \\
Grade 12 score, \% $(n=142)$ & $78.08(6.88)$ & 34.60 & $60.00-94.00$ \\
Study hours per week $(n=142)$ & $45.45(11.99)$ & 66.00 & $18.00-84.00$ \\
First-unit exam score (\%), theory $(n=139)$ & $50.48(14.91)$ & 73.33 & $3.33-76.67$ \\
First-unit exam score (\%), practical $(n=139)$ & $52.34(17.12)$ & 76.54 & $10.00-86.54$ \\
\hline
\end{tabular}


Table 3 Preferred mode of learning and their subcategories among preclinical medical students

\begin{tabular}{|l|l|l|l|l|}
\hline & Category & Frequency & Percentage & Total \\
\hline Unimodal & Visual (V) & 2 & 1.4 & $66(46.48 \%)$ \\
& Aural (A) & 21 & 14.8 & \\
& Read/write (R) & 1 & 0.7 & 37 (26.06\%) \\
& Kinesthetic (K) & 42 & 29.6 & \\
& VA & 2 & 1.4 & \\
& VR & 1 & 0.7 & \\
& VK & 3 & 2.1 & \\
& AR & 1 & 0.7 & $16(11.27 \%)$ \\
& AK & 26 & 18.3 & \\
& RK & 4 & 2.8 & 0.7 \\
& VAR & 1 & 3.5 & 23 (I6.20\%) \\
\hline
\end{tabular}

two categories with respect to grade achieved in $10+2$ (or equivalent), marks scored in first-unit theory and practical exams and study hours per week (Table 4). Though a statistically insignificant association $(P>0.05)$ was noted, more high achievers in the anatomy theory exam were unimodal learners $(53.8 \%)$ than multimodal learners (46.2\%) and more low achievers were multimodal $(52.6 \%)$. Unlike this, more high and low achievers in the practical exam were found to be multimodal learners than unimodal.

In box-and-whisker plots, differences were more marked in $25 \%$ of subjects achieving low scores or spending less time on their studies than the other students (Figure 3): 25\% of students who got the lowest marks in anatomy (theory) in sample subsets were found to have a higher proportion of unimodal learners than multimodal. A similar difference also existed for anatomy marks in the practical examination, but this was minimal compared to theory exam marks. Study hours were fewer in multimodal learners compared to unimodal learners among the $25 \%$ of students who spent the least time on their studies. In the case of marks scored in higher secondary school (HSS) examinations, the difference can be appreciated in both the first and fourth quartiles of data. The median value for unimodal learners was slightly higher than multimodal learners.

Before further inferential statistical analysis, continuous variables were checked for normality using the Shapiro-Wilk test (Table 6). Data points of only one variable were found to be normally distributed $(P>0.05)$. According to the distribution pattern, the unpaired Student's $t$-test, Mann-Whitney $U$ test, and Spearman's correlation test were used for inferential statistics to see the differences and correlations among the variables.

To assess statistical differences in marks, study hours and ages of students between unimodal and multimodal learners, independent $t$-tests and Mann-Whitney $U$ tests were applied. None of the continuous variables was found to be significantly different between two types of learners ( $P>0.05$; Table 7$)$.

VARK scores were calculated by adding the individual score of each component of the VARK for each subject. These scores were compared between sexes to see the difference (Table 8). Total V, K, and VARK scores were higher among male students than female students. The difference in total $\mathrm{K}$ scores $(7.96 \pm 2.35$ in males vs $6.96 \pm 2.43$ in females) was statistically significant $(P=0.019)$. Total A and $\mathrm{R}$ scores were higher among female students than male students, but the difference was not statistically significant $(P<0.05)$.

Finally, bivariate correlation analysis was done to calculate correlation coefficients for different variables. $\mathrm{V}$ scores were significantly correlated with $\mathrm{R}$ scores $\left(r_{\mathrm{s}}=0.17\right)$ and $\mathrm{K}$ scores $\left(r_{\mathrm{s}}=0.64\right)$. R score was negatively correlated with HSS marks $\left(r_{\mathrm{s}}=-0.20\right)$ and practical marks in anatomy $\left(r_{\mathrm{s}}=-0.18\right)$. $\mathrm{K}$ scores were correlated with study hours $\left(r_{\mathrm{s}}=0.25\right)$. HSS marks were significantly correlated with anatomy marks in theory $\left(r_{\mathrm{s}}=0.17\right)$ and practical $\left(r_{\mathrm{s}}=0.27\right)$ exams. Marks in anatomy theory and anatomy practical exams were positively correlated $\left(r_{\mathrm{s}}=0.71\right)$, with statistical significance (Table 9).

\section{Discussion}

Knowledge of the learning styles of students and the characteristics affecting them is important for teacher to improve 


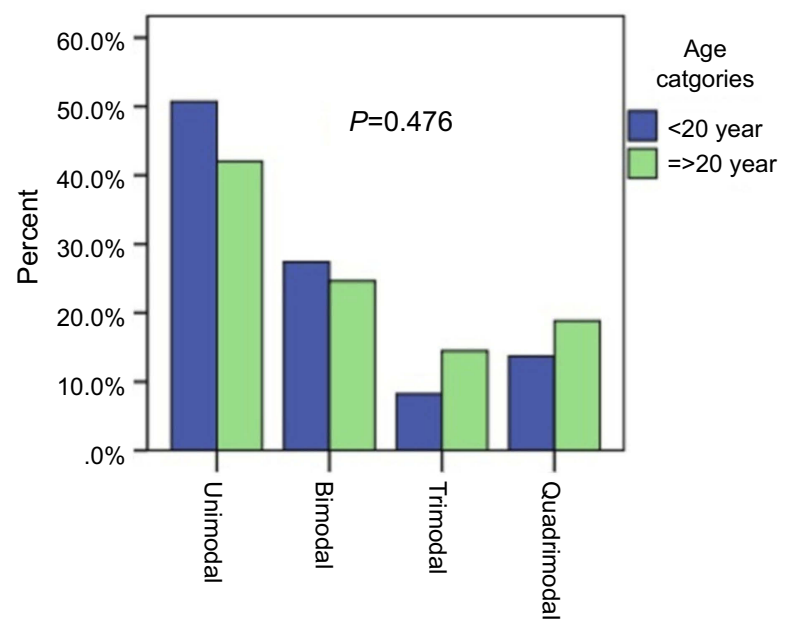

Preferred modality

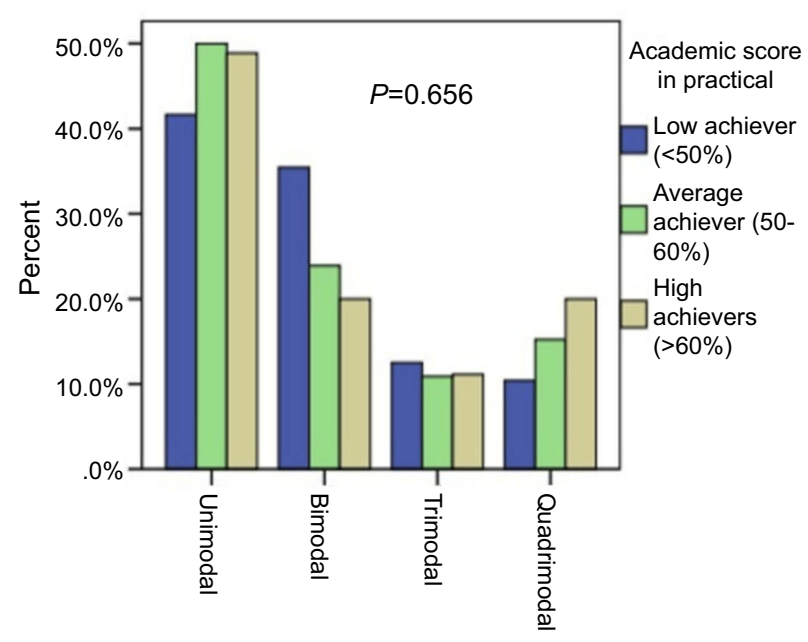

Preferred modality

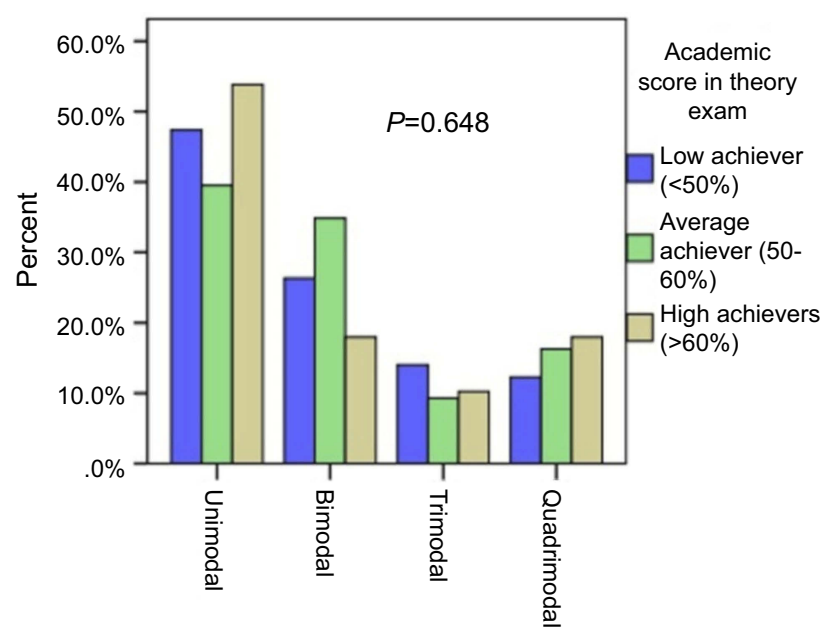

Preferred modality

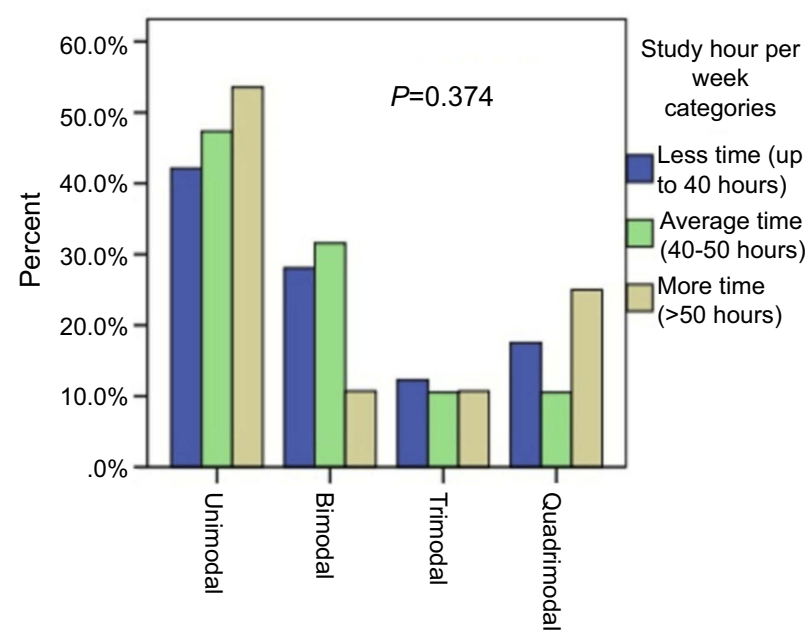

Preferred modality

Figure I Distribution of students' preferred modes of learning by age and academic performance.

lesson plans and develop teaching methodologies to adapt them to their needs. This can also be useful in overcoming the traditional method of the teacher-centered method of teaching. ${ }^{22}$ Many factors like learner motivation, study skills, and the ability to assess their own learning needs have been identified as good predictors of student performance, ${ }^{23}$ and synchronizing a teaching style with the learning preferences of learners may also bring additional benefits for the learners. Students feel happier when they are taught using their preferred learning mode, ie, visual, auditory, read/write, or kinesthetic. ${ }^{19}$ The most challenging situation for a medical teacher comes during imparting boundless information within a limited period and also in a way that students can understand and interpret the information effectively. ${ }^{24}$

The present study was conducted among 142 preclinical medical students recently enrolled in their courses. Results showed that the majority of the students $(53.52 \%)$ were multimodal learners with more than one component of VARK. This result is in accordance with study result from Indian, ${ }^{25-27}$ Iranian, ${ }^{28}$ and West Indian students. ${ }^{29}$ In contrast to this, some studies have shown the unimodal type of learning was a choice for a majority of students. ${ }^{30-33}$ Comparison of the present study with some of the previous studies is shown in Table 10. Among unimodal learners, most of the students were kinesthetic learners (29.6\%), followed by aural, visual and reading/writing. Similarly, the most preferred mode among bimodal and trimodal learners was AK (18.3\%) and ARK (5.6\%), respectively. Kinesthetic learning is also dominant among preclinical students from other parts of the world. ${ }^{25,27,33}$ Among multimodal learners, the present study showed the AK combination to be the predominant learning style, found in $18.3 \%$ of the total sample. Results of 

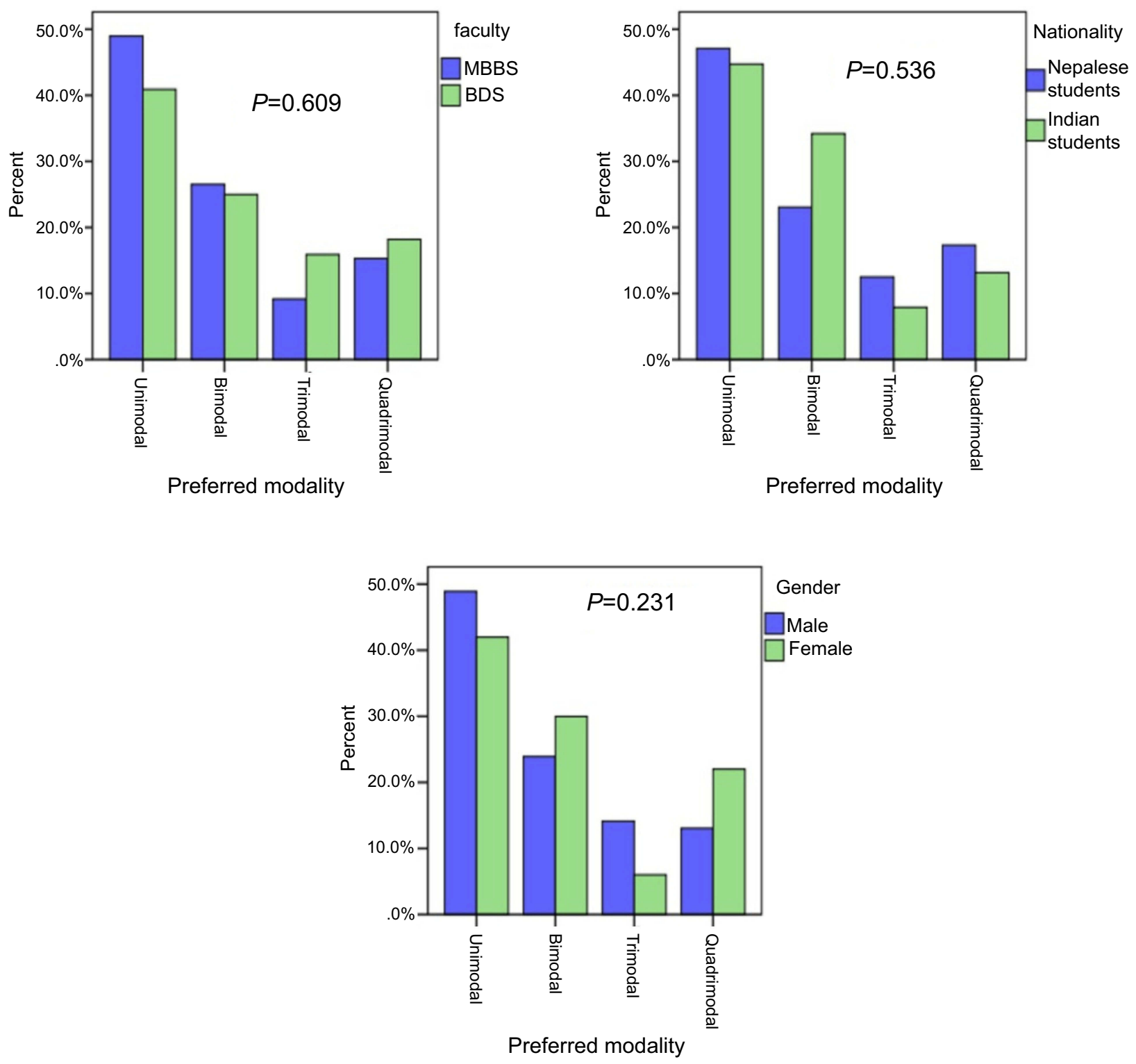

Figure 2 Distribution of students' preferred modes of learning by sex, faculty, and nationality.

Abbreviations: MBBS, Bachelor of Medicine-Bachelor of Surgery; BDS, Bachelor of Dental Surgery.

this study are in accordance with findings of a study done among Indian preclinical students. ${ }^{25}$ Another study done among medical students from Ireland also showed the bimodal mode of learning to be predominant. ${ }^{32}$ Many other studies found a quadrimodal preference to be predominant. $^{26,27,29,30}$

\section{Learning style and sex}

The influence of sex on learning styles is of interest to many researchers. In the present study, both males and females were found to have multimodal preferences.
Trimodal preference was the least preferred for females, whereas quadrimodal was least preferred for males. Total V, K, and VARK scores were higher among male students than female students. Only the total $\mathrm{K}$ score $(7.96 \pm 2.35$ in males and $6.96 \pm 2.43$ in females) was significantly higher $(P=0.019)$ in males than females. Results were consistent with many previous studies, ${ }^{25,26,28-30}$ which also showed statistically significant differences. A study done among Indian preclinical students showed statistically significant sex differences in learning. ${ }^{31}$ Another study done among 

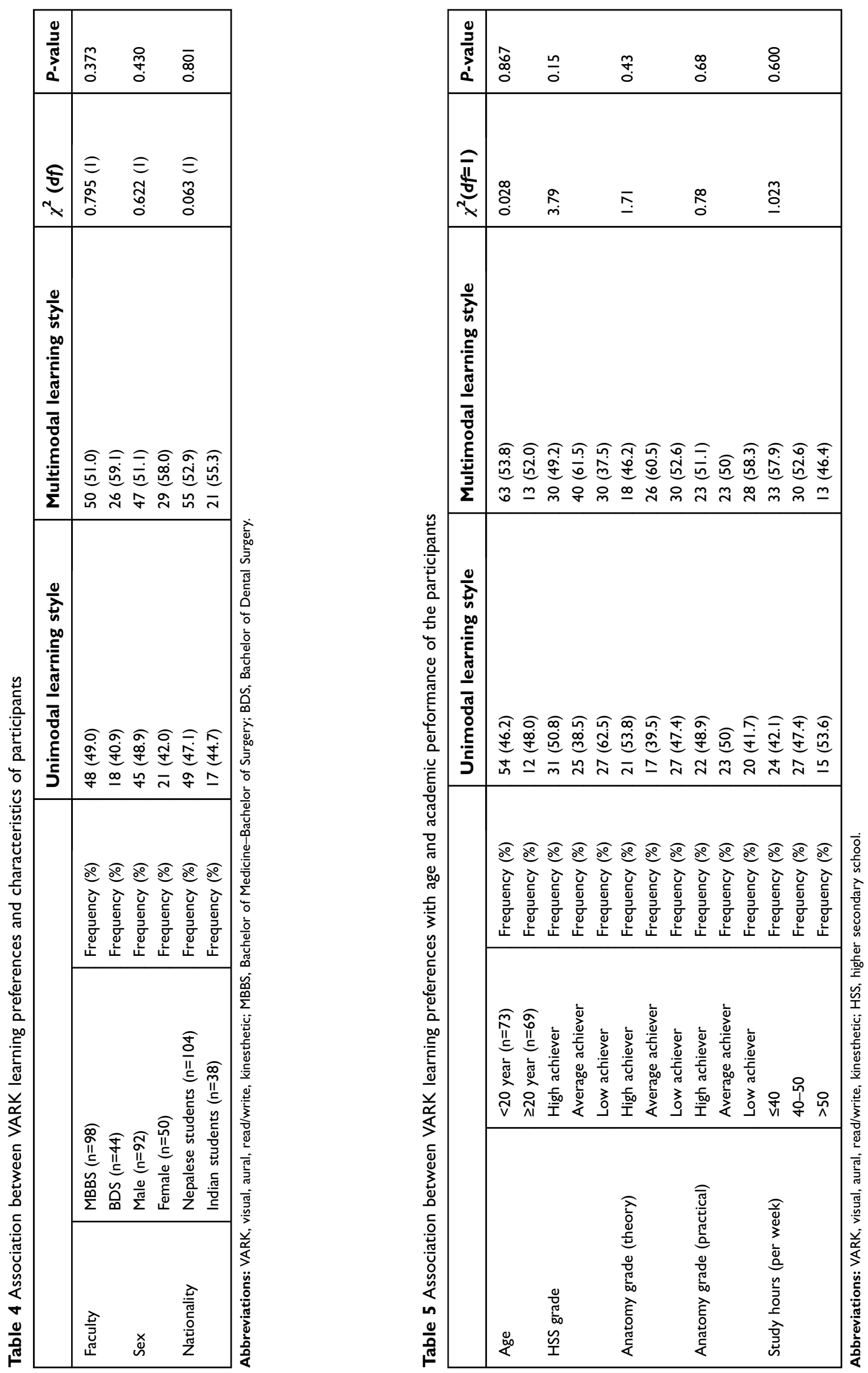

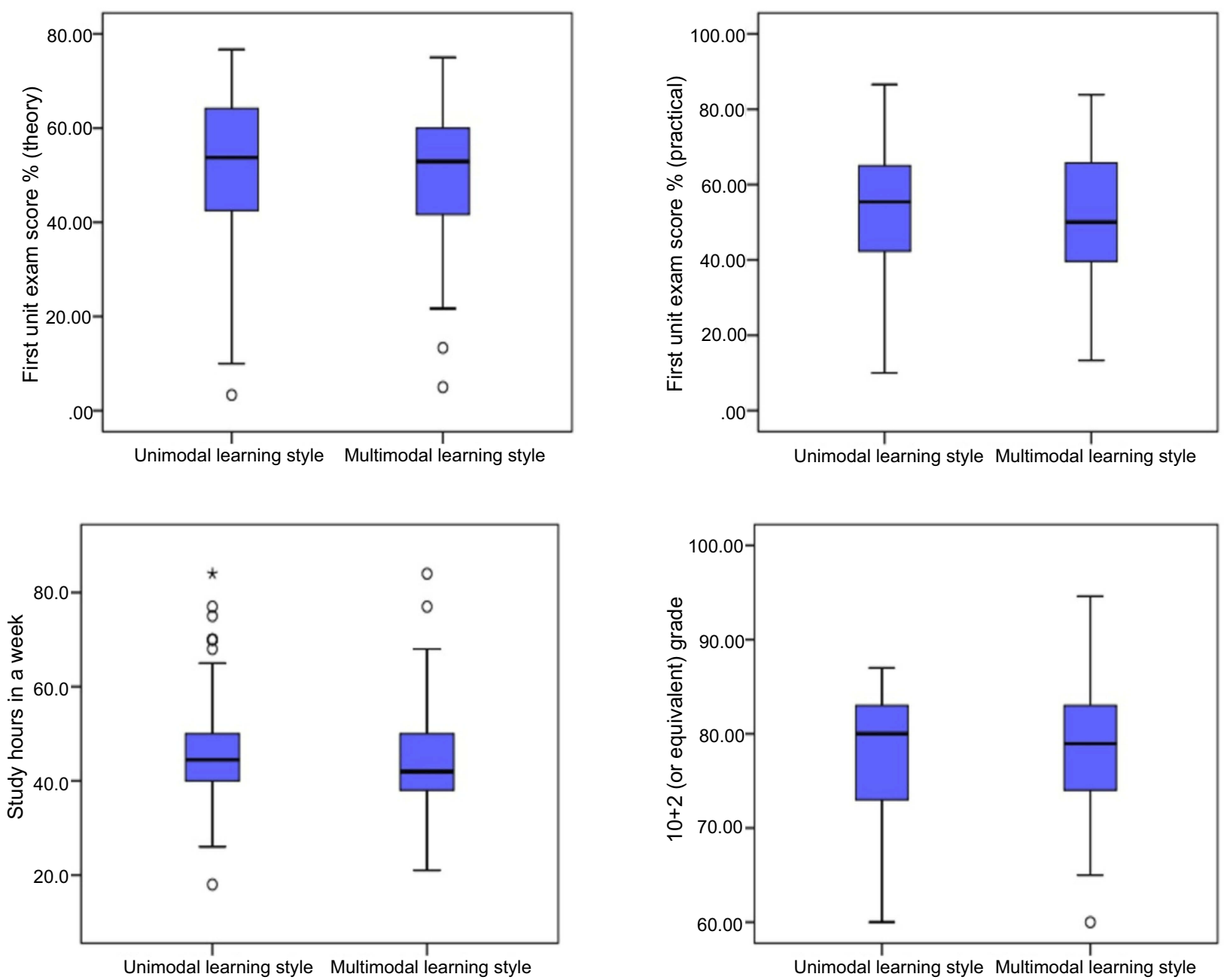

Figure 3 Box-and-whisker plots showing the relationship between categorical variable (learning styles) and scale variables (academic performance). Note: Outliers shown as circles and extreme outliers as asterisks.

preclinical medical students of Maharashtra showed sex-specific differences when compared for unimodal learning style only. ${ }^{27}$

\section{Learning style and academic achievement} It is well acknowledged that assessment motivates learning. ${ }^{34}$ Various factors play a role in determining the learning style of students. Studies using the VARK inventory among medical students can be found in different parts of the world, but results have not been consistent. Similarly, the relationship of academic performance with learning modes has also been inconsistent. A study done on a particular group cannot be generalized to other groups in the population. Therefore, we tried to analyze the relationship between assessment outcome, which was measured in terms of exam scores, and learning styles. ${ }^{35}$

We compared the distribution of learning styles with marks in first-unit anatomy exam, incorporating practical and theory exam marks separately. More students with high achievement in the theory exam were unimodal, while in the practical both high and low achievers were more likely multimodal learners. Though such differences, none was statistically significant (Table 6). Similar results were observed in a study by Shenwai and Patil, in which no significant differences were observed between theory and practical percentages of unimodal, bimodal, and multimodal learners. ${ }^{31}$

ifferences in academic achievement among different learning styles might be due to differences in effectiveness of learning and matching learning methods to students' learning styles. Remembering facts and figures is important for attempting theory questions, while motor skills along with theory knowledge are important for attempting practical questions. This was reflected in the present study, with positive correlations of practicalanatomyexam scores with kinesthetic scores and negative correlations with V, A 
Table 6 Tests for normality for all quantitative variables

\begin{tabular}{|c|c|c|c|c|}
\hline & \multicolumn{2}{|c|}{ Kolmogorov-Smirnov } & \multicolumn{2}{|c|}{ Shapiro-Wilk } \\
\hline & Statistic & $P$ & Statistic & $\mathbf{P}$ \\
\hline Age & 0.204 & $<0.001$ & 0.909 & $<0.001$ \\
\hline $10+2$ (or equivalent) grade & 0.098 & 0.002 & 0.967 & 0.002 \\
\hline Study hours in a week & 0.156 & $<0.001$ & 0.935 & $<0.001$ \\
\hline First-unit exam score, \% (theory) & 0.083 & 0.020 & 0.963 & 0.001 \\
\hline First-unit exam score, \% (practical) & 0.100 & 0.002 & 0.984 & 0.095 \\
\hline Total visual $(V)$,aural $(A)$, read/write $(R)$, kinesthetic $(K)$ score & 0.152 & $<0.001$ & 0.933 & $<0.001$ \\
\hline Total A score & 0.114 & $<0.001$ & 0.957 & $<0.001$ \\
\hline Total R score & 0.146 & $<0.001$ & 0.956 & $<0.001$ \\
\hline Total K score & 0.104 & 0.001 & 0.977 & 0.020 \\
\hline Total VARK score & 0.109 & $<0.001$ & 0.925 & $<0.001$ \\
\hline
\end{tabular}

Note: $P>0.05$ signifies normal distribution of the data points of the variable.

Table 7 Comparison of quantitative variables between unimodal and multimodal learners (independent-sample t-test and MannWhitney $U$ test)

\begin{tabular}{|c|c|c|c|c|}
\hline & Unimodal vs multimodal learning & Mean rank & Mann-Whitney U & $P$-value \\
\hline \multirow[t]{2}{*}{ Age } & Unimodal learning style & 70.89 & $2,467.50$ & 0.863 \\
\hline & Multimodal learning style & 72.03 & & \\
\hline \multirow[t]{2}{*}{$10+2$ (or equivalent) grade } & Unimodal learning style & 72.08 & $2,469.50$ & 0.875 \\
\hline & Multimodal learning style & 70.99 & & \\
\hline \multirow[t]{2}{*}{ Study hours in a week } & Unimodal learning style & 75.20 & $2,264.00$ & 0.317 \\
\hline & Multimodal learning style & 68.29 & & \\
\hline \multirow[t]{2}{*}{ First-unit exam score, \% (theory) } & Unimodal learning style & 71.93 & $2,279.50$ & 0.596 \\
\hline & Multimodal learning style & 68.30 & & \\
\hline \multirow[t]{3}{*}{ First-unit exam score, \% (practical) } & & Mean (SD) & Mean difference & $P$-value \\
\hline & Unimodal learning style & $53.13(17.60)$ & 1.492 & 0.610 \\
\hline & Multimodal learning style & $51.64(16.77)$ & & \\
\hline
\end{tabular}

Table 8 Individual and total VARK scores based on sex

\begin{tabular}{|c|c|c|c|c|c|c|}
\hline & Sex & Mean \pm SD & SEM & Mean rank & $U$ & $P$-value \\
\hline \multirow[t]{2}{*}{ Total V score } & Male & $4.59 \pm 2.60$ & 0.27 & 74.47 & $2,027.0$ & 0.239 \\
\hline & Female & $4.06 \pm 2.04$ & 0.29 & 66.04 & & \\
\hline \multirow[t]{2}{*}{ Total A score } & Male & $6.22 \pm 3.02$ & 0.32 & 67.96 & $1,974.5$ & 0.162 \\
\hline & Female & $6.72 \pm 2.53$ & 0.36 & 78.01 & & \\
\hline \multirow[t]{2}{*}{ Total R score } & Male & $3.91 \pm 1.98$ & 0.21 & 68.88 & $2,059.0$ & 0.298 \\
\hline & Female & $4.42 \pm 2.43$ & 0.34 & 76.32 & & \\
\hline \multirow[t]{2}{*}{ Total K score } & Male & $7.96 \pm 2.35$ & 0.24 & 77.44 & I,753.5 & 0.019 \\
\hline & Female & $6.96 \pm 2.43$ & 0.34 & 60.57 & & \\
\hline \multirow[t]{2}{*}{ Total VARK score } & Male & $22.67 \pm 6.16$ & 0.64 & 71.59 & $2,291.5$ & 0.97 \\
\hline & Female & $22.16 \pm 5.04$ & 0.71 & 71.33 & & \\
\hline
\end{tabular}

Abbreviation: VARK, visual,aural, read/write, kinesthetic.

and R scores of VARK. More students preferred to remember facts from lectures and interactive sessions using only one sensory modality, which was reflected in the higher percentage of unimodal learners achieving higher marks in the theory exam. A study among preclinical students from Malaysia showed, though not statistically significant, more unimodal learners were mid/high achievers $(82.2 \%)$ than multimodal learners. ${ }^{36}$ Due to the use of multiple 


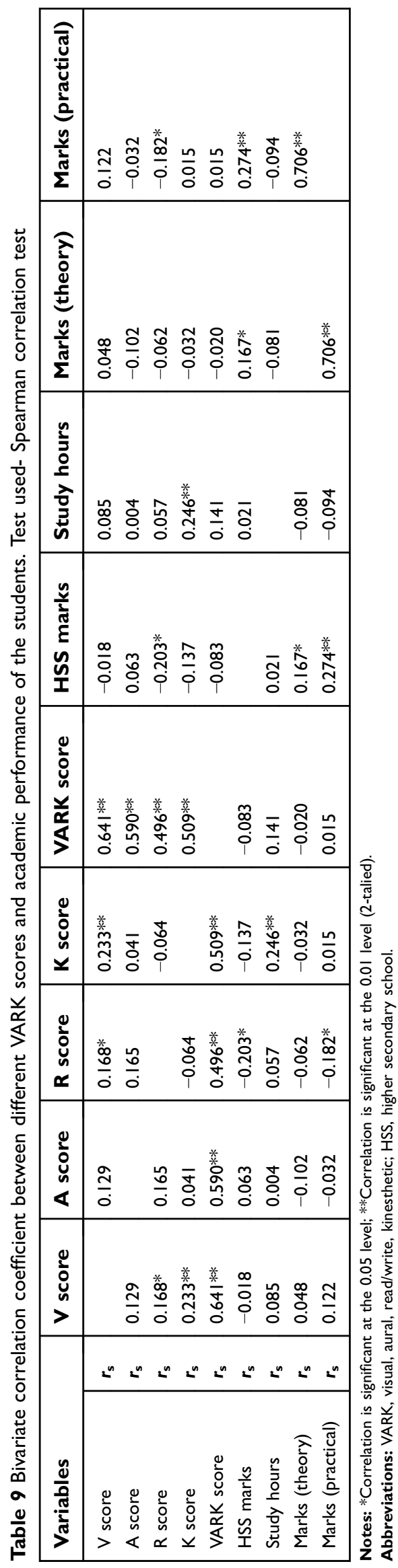

modalities in identifying and finding various anatomical structures, high achievers in the practical exam were more likely to be multimodal learners than unimodal, but this result was not statistically significant. Other studies on dental students from Iran and the West Indies did not show significant differences between learning styles and mean academic scores either. ${ }^{37,38}$

\section{Learning styles and age}

We also analyzed learning-style preferences between two age-groups (above and below 20 years). More multimodal learners were found in both age-groups. Among the unimodal learners, the most preferred style was kinesthetic followed by aural in both groups. Liew et al also found that both groups of students (above and below 20 years) were kinesthetic learners. However, a higher proportion of those aged 20 years and above were multimodal learners $(21 \%)$ than students aged $<20$ years $(11.5 \%) .{ }^{36}$

\section{Learning styles and faculty}

The present study showed that most MBBS and BDS students preferred multimodal learning, with a slightly higher proportion among BDS students (59.1\%) than MBBS students (51.0\%). The proportion of students with unimodal and bimodal styles was higher in MBBSstudents, while the proportion of trimodal and quadrimodal styles was higher in BDS students. A study on Malaysian students from different faculties (medicine, dentistry, and pharmacy) showed that individual VARK scores were highest for medicine, followed by dentistry and pharmacy. This difference was not statistically significant. ${ }^{39}$ In contrast to this, the present study found that mean $\mathrm{V}$ and $\mathrm{K}$ scores were higher among MBBS students, while $\mathrm{A}$ and $\mathrm{R}$ scores were higher among BDS students. These differences were not statistically significant either. A similar study was done among Indian students from different faculties. Results of that study showed that all faculties were predominantly kinesthetic learners. When multimodal learners were compared with unimodal learners among the faculties, the difference was significant. ${ }^{40}$

The results of this study should facilitate medical teachers in adopting multiple modes of teaching methodologies, rather than one-way didactic lectures. Moreover, lesson plans andcurriculumdesign should take into account students' preferred learning styles and be designed in such a way that learners are encouraged, which should be reflected on teaching-learning interventions accordingly. 
Table 10 Comparison of present study with previous studies. Most common learning modes are presented within brackets

\begin{tabular}{|l|l|l|l|l|}
\hline \multirow{2}{*}{ Reference } & Region & Sample size & \multicolumn{2}{l|}{ Learning style } \\
\cline { 3 - 5 } & & & Unimodal & Multimodal \\
\hline 25 & India & 152 & $48 \%(\mathrm{~K}=35 \%)$ & $52 \%($ AK) \\
30 & India & 121 & $53.8 \%(\mathrm{~V}=24.1 \%)$ & $46.2 \%($ VARK=42.3\%) \\
31 & India & 150 & $58 \%$ & $42 \%$ \\
33 & Saudi Arabia & 110 & $59 \%(\mathrm{~K}=15 \%)$ & $41 \%$ \\
29 & West Indies & 500 & $31.3 \%(\mathrm{~A}=14.24)$ & $68.7 \%($ VARK=24.14\%) \\
26 & India & 273 & $36.6 \%(\mathrm{~V}=12.22 \%)$ & $63.4 \%($ VARK=33.3\%) \\
32 & Ireland & 327 & $57.8 \%$ & $42.2 \%($ bimodal=23.5\%) \\
28 & Iran & 80 & $47.5 \%(\mathrm{~A}=29.78 \%)$ & $52.5 \%$ \\
27 & India & 142 & $33 \%(\mathrm{~K}=14.52 \%)$ & $67 \%($ VARK=31.49\%) \\
Present study & Nepal & $46.48 \%(\mathrm{~K}=29.6 \%)$ & $53.52 \%(\mathrm{AK}=18.3 \%)$ \\
\hline
\end{tabular}

Abbreviation: VARK, visual, aural, read/write, kinesthetic.

\section{Limitations}

This study did not explore the role of learning environment, learner' motivation, classroom environment, study skills, or ability to assess one's own learning preferences in the academic performance of the students. The educational background of students may have influenced performance. As learning-style preferences are not fixed and likely to change as students mature and progress through their career, a longitudinal study should be done to observe such changes.

\section{Conclusion}

From this VARK survey, we concluded that though our undergraduate students were diverse in their learning styles, they were mostly multimodal. The kinesthetic mode was most preferred among unimodal learners, and the combination of aural and kinesthetic most preferred among multimodal learners. $V$ scores were found to be correlated with $\mathrm{K}$ and $\mathrm{R}$ scores. $\mathrm{R}$ scores were negatively correlated with marks in the practicalanatomy exam. Though learning styles were found to vary according to sex, age, nationality, and academic performance, the differences were not statistically significant.

\section{Acknowledgments}

The authors acknowledge Dr Bishal Babu Basnet and Dr Jamal Giri for English-language correction.

\section{Disclosure}

The authors report no conflicts of interest in this work.

\section{References}

1. Vision, mission \& goal. http://bpkihs.edu/?introduction/vision.html. Accessed July 7, 2017.

2. Dangwal R, Mitra S. Learning styles and perceptions of self. Int Educ J. 1999;1(1):61-71.

3. Nuzhat A, Salem RO, Quadri MS, Al-Hamdan N. Learning style preferences of medical students: a single-institute experience from Saudi Arabia. Int J Med Educ. 2011;2:70-73. doi:10.5116/ijme.4e36.d31c

4. Mon AA, Fatini A, Ye CW, Barakat MA, Jen PL, Lin TK. Original article learning style preferences among pre-clinical medical students. J Med Allied Sci. 2014;4(1):22-27.

5. Lujan HL, DiCarlo SE. First-year medical students prefer multiple learning styles. Adv Physiol Educ. 2006;30(1):13-16. doi:10.1152/ advan.00045.2005

6. Barclay SM, Jeffres MN, Bhakta R. Educational card games to teach pharmacotherapeutics in an advanced pharmacy practice experience. Am J Pharm Educ. 2011;75(2):1-7.

7. Corbin A. Assessing differences in learning styles: age, gender and academic performance at the tertiary level in the Caribbean. Caribb Teach Sch. 2017;7(1):67-91.

8. Mehta M, Sagar R. Study Skill. In: Mehta M, Sagar R, eds. A Practical Approach to Cognitive Behaviour Therapy for Adolescents. New Delhi: Springer India; 2015:429. doi:10.1007/978-81-322-2241-5

9. Fleming ND, Mills C. Not another inventory, rather a catalyst for reflection. To Improv Acad. 1992;1(1):137-144. doi:10.1002/j.23344822.1992.tb00213.x

10. Alkhasawneh E. Using VARK to assess changes in learning preferences of nursing students at a public university in Jordan: implications for teaching. Nurse Educ Today. 2013;33(12):1546-1549.

11. Baykan Z, Naçar M. Learning styles of first-year medical students attending Erciyes university in Kayseri, Turkey. Adv Physiol Educ. 2007;31(2):158-160. doi:10.1152/advan.00043.2006

12. Mustafa AG, Allouh MZ, Mustafa IG, Hoja IM. Anatomy learning styles and strategies among Jordanian and Malaysian medical students: the impact of culture on learning anatomy. Surg Radiol Anat. 2013;35(5):435-441. doi:10.1007/s00276-012-1067-z

13. Mitchell BS, Xu Q, Jin L, Patten D, Gouldsborough I. A crosscultural comparison of anatomy learning: learning styles and strategies. Anat Sci Educ. 2009;2(2):49-60. doi:10.1002/ase.73

14. Farkas GJ, Mazurek E, Marone JR. Learning style versus time spent studying and career choice: which is associated with success in a combined undergraduate anatomy and physiology course? Anat Sci Educ. 2016;9(2):121-131. doi:10.1002/ase.1563 
15. Parashar R, Hulke S, Pakhare A. Learning styles among first professional northern and central India medical students during digitization. Adv Med Educ Pract. 2018;10:1-5. doi:10.2147/AMEP.S182790

16. Marahatta SB, Dixit H. Students' perception regarding medical education in Nepal. Kathmandu Univ Med J. 2008;6(22):273-283.

17. Shah N. Undergraduate medical education in Nepal: need for change. J Kathmandu Med Coll. 2015;4(11):1-2.

18. Leite WL, Svinicki M, Shi Y. Attempted validation of the scores of the VARK: learning styles inventory with multitrait-multimethod confirmatory factor analysis models. Educ Psychol Meas. 2010;70:323-339. doi:10.1177/0013164409344507

19. Fitkov-Norris ED, Yeghiazarian A. Validation of VARK learning modalities questionnaire using Rasch analysis. J Phys Conf Ser. 2015;588(1):012048. doi:10.1088/1742-6596/588/1/012048

20. Slack N, Norwich B. Evaluating the reliability and validity of a learning styles inventory: a classroom-based study. Educ Res. 2007;49(1):51-63. doi:10.1080/00131880701200765

21. Faul F, Erdfelder E, Lang A-G, Buchner A. G*power: a flexible statistical power analysis program for the social, behavioral, and biomedical sciences. Behav Res Methods. 2007;39(2):175-191.

22. Pour MS, Ghoreishinia G, Zare S, Arbabisarjou A. Identification of medical students' learning styles in terms of gender. Glob J Health Sci. 2016;9(4):76. doi:10.5539/gjhs.v9n4p76

23. Credé M, Kuncel NR. Study habits, skills, and attitudes: the third pillar supporting collegiate academic performance. Perspect Psychol Sci. 2008;3(6):425-453. doi:10.1111/j.1745-6924.2008.00089.x

24. Niazur Rahman SM, Alam T, Alam NN, Haque MZ, Alam T. Medical undergraduates preference in learning style: a single-institute experience from Bangladesh. Kuwait Med J. 2017;49(1):12-16.

25. Balasubramaniam G. K I. A study of learning style preferences among first year undergraduate medical students using VARK model. Educ Med J. 2016;8(4):15-21. doi:10.5959/eimj.v8i4.440

26. Jansale VN, Balappa IP, Odappa GH, Veerappa YV. Assessment of preferred learning modalities of undergraduate medical students using the visual-aural-read/write-kinesthetic questionnaire and the impact of gender. J Adv Clin Res Insights. 2015;2:135-139. doi:10.15713/ins.jcri.62

27. Shete AN. Gender influences on learning styles of undergraduate medical students. Int J Med Sci Educ. 2016;3(3):233-241.

28. Zamani N, Kaboodi A. Evaluation of the VARK model learning styles selection in medical students. Heal Res J. 2017;2(2):109-115. doi:10.18869/acadpub.hrjbaq.2.2.109

29. Urval RP, Kamath A, Ullal S, Shenoy AK, Shenoy N, Udupa LA. Assessment of learning styles of undergraduate medical students using the VARK questionnaire and the influence of sex and academic performance. AJP Adv Physiol Educ. 2014;38(3):216-220. doi:10.1152/ advan.00024.2014
30. Soundariya K, Deepika V, Kalaiselvan G. A study on the learning styles and learning approaches among medical students. Natl J Physiol Pharm Pharmacol. 2017;7(10):1020-1025. doi:10.5455/ njppp.2017.7.0413011052017

31. Shenwai MR, Patil KB. Assessment of learning style preferences and their influence on gender $\&$ academic performance among first year medical undergraduate students. Natl J Integr Res Med. 2017;8 (1):109-116

32. O'Mahony SM, Sbayeh A, Horgan M, O'Flynn S, O'Tuathaigh CMP. Association between learning style preferences and anatomy assessment outcomes in graduate-entry and undergraduate medical students. Anat Sci Educ. 2016;9(4):391-399. doi:10.10 02 /ase. 1600

33. El Sayed MM, Mohsen DM, Dogheim RS, Zain HH, Ahmed D. Assessment of learning styles for medical students. Int J Manag Appl Sci. 2016;2(7):158-162.

34. Sopian A. A study on learning styles among Arabic language students at Universiti Teknologi Mara, Malacca campus. IOSR J Humanit Soc Sci. 2013;15(4):38-40. doi:10.9790/0837-1543840

35. Khanal L, Shah S, Koirala S. Exploration of preferred learning styles in medical education using VARK modal. Russ Open Med J. 2014;3:0305. doi:10.15275/rusomj.2014.0305

36. Liew S-C, Sidhu J, Barua A. The relationship between learning preferences (styles and approaches) and learning outcomes among pre-clinical undergraduate medical students. BMC Med Educ. 2015;15(1):44. doi:10.1186/s12909-015-0327-0

37. Akhondali Z, Dianat M, Radan M. Relationship between learning style and academic status of Babol dental students. Electron Physician. 2015;7(1):971-976. doi:10.14661/2015.971-976

38. Ojeh N, Sobers-Grannum N, Gaur U, Udupa A, Majumder A. Learning style preferences: a study of pre-clinical medical students in Barbados. J Adv Med Educ Prof. 2017;5(4):185-194.

39. Wong RSY, Siow HL, Kumarasamy V, Suhaimi NSF. Interdisciplinary and inter-institutional differences in learning preferences among Malaysian medical and health sciences students. $J$ Adv Med Educ Prof. 2017;5(4):164-171.

40. Joshil Kumar B, Sushma S, Kumar N, Binod Kumar B, Ajay S, Sharma K. Difference in learning style preference of medical,dental and B pharma students. Int J Med Med Sci. 2011;1(2):37-41.
Advances in Medical Education and Practice

\section{Publish your work in this journal}

Advances in Medical Education and Practice is an international, peerreviewed, open access journal that aims to present and publish research on Medical Education covering medical, dental, nursing and allied health care professional education. The journal covers undergraduate education, postgraduate training and continuing medical education including emerging trends and innovative models linking education, research, and health care services. The manuscript management system is completely online and includes a very quick and fair peer-review system. Visit http://www.dovepress.com/testimonials.php to read real quotes from published authors. 